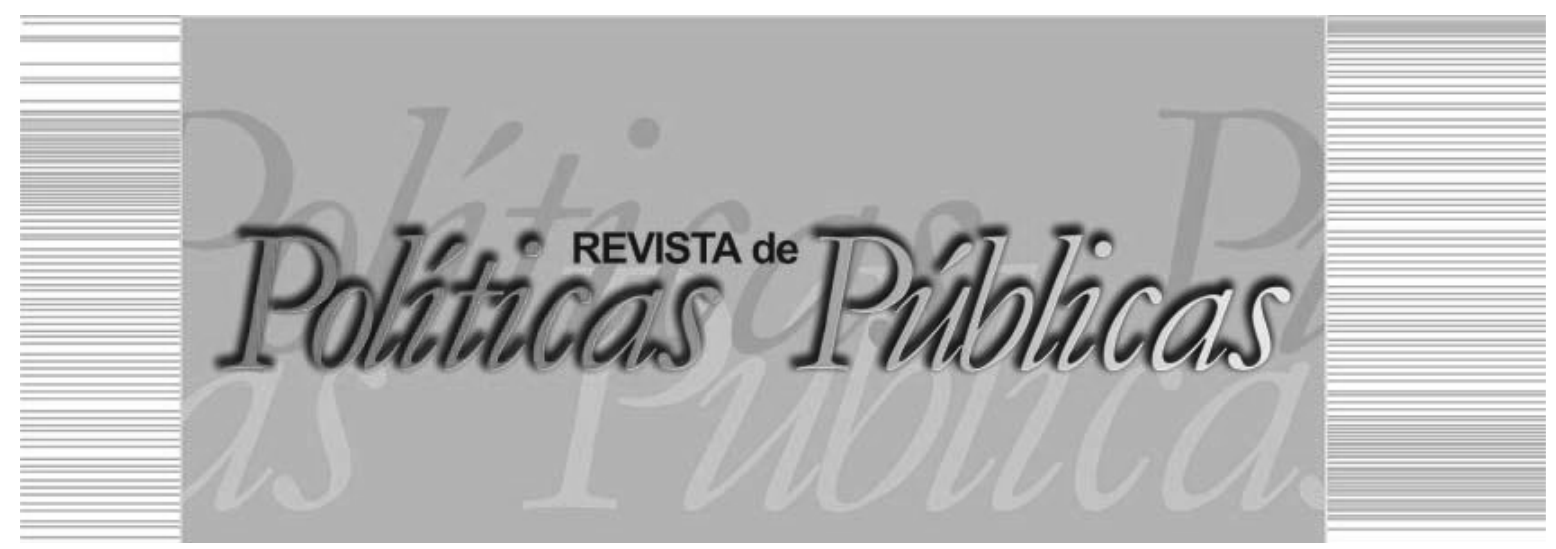

\title{
REDES E ATIVISMO EM POLITICAS PÚBLICAS: \\ a construção da Política Nacional de Educação Museal (PNEM)
}

\author{
Luciana Conrado Martins ${ }^{1}$ \\ Oswaldo Gonçalves Junior ${ }^{2}$
}

\section{Resumo}

Este artigo tem como objetivo apresentar o resultado de uma pesquisa teórico-empírica sobre o processo de construção da Política Nacional de Educação Museal (PNEM). Publicada no final de 2017, a PNEM consolida os anseios dos educadores de museus por instituições e processos museológicos voltados para a educação de seus públicos. Sua construção revela uma rede em âmbito nacional, envolvendo sub-redes estaduais e atores locais, cujos papéis de formuladores e implementadores da política coincidem. $\mathrm{O}$ ativismo de atores-chave, empreendedores de políticas, com trânsito nas estruturas governamentais, respondem pela estratégia de ativação da rede. Utilizando análise documental e observação, o artigo descreve esse processo de construção e procura analisá-lo sob a ótica da governança de redes de políticas públicas. Busca ampliar a compreensão sobre o potencial e os limites de arranjos desse tipo, apontando o caráter performático da rede quando confrontada com a literatura.

Palavras-chave: políticas públicas culturais, Política Nacional de Educação Museal, educação em museus, rede de políticas públicas.

\footnotetext{
Bacharel em História, Doutora em Educação pela Universidade de São Paulo (USP). E-mail: lucianamartins@percebeeduca.com.br / Endereço: Universidade de São Paulo - USP: Rua da Reitoria, 374, Cidade Universitária, São Paulo - SP. CEP: 05508-220

2 Bacharel e Licenciado em História, Doutor em Administração Pública e Governo, Professor Doutor e Coordenador do Curso Bacharelado em Administração Pública da Faculdade de Ciências Aplicadas (FCA) da Universidade Estadual de Campinas (UNICAMP), Professor Pleno no Mestrado Interdisciplinar em Ciências Humanas e Sociais Aplicadas (ICHSA/UNICAMP). E-mail: osgoju@gmail.com / Endereço: Universidade Estadual de Campinas - UNICAMP - Faculdade de Ciências Aplicadas, Rua Pedro Zaccaria, Jardim Santa Luiza - Limeira, SP. CEP: 13484-350
} 
NETWORKS AND ACTIVISM IN PUBLIC POLICIES: the construction of the National Policy of Museum Education (PNEM)

\begin{abstract}
This article aims to present the result of a theoretical-empirical research on the process of construction of the National Policy of Museum Education (PNEM). Published at the end of 2017, PNEM consolidates the wishes of museum educators for museological institutions and processes aimed at the education of its audiences. Its construction reveals a network at the national level, involving subnetworks and local actors, whose roles of policy makers and implementers coincide. The activism of key actors, policy-makers, with transit in the governmental structures, respond by the strategy of activation of the network. Using documentary analysis and observation, the article describes this construction process and seeks to analyze it from the point of view of the governance of public policy networks. It seeks to broaden the understanding of the potential and limits of such arrangements, pointing to the performative character of the network when confronted with literature.
\end{abstract}

Key words: Cultural public policies, National Policy of Museum Education, education in museums, public policies network.

\title{
1 INTRODUÇÃO
}

No final do ano de 2017, depois de um intenso processo de consultas públicas e mobilização dos profissionais da área, foi publicada, por meio de uma portaria do Instituto Brasileiro de Museus, a Política Nacional de Educação Museal (PNEM) (Portaria n ${ }^{\circ} 422$, de 30 de novembro de 2017). Com cinco princípios e 19 diretrizes distribuídas em três eixos (Gestão, Profissionais, formação e pesquisa e Museus e sociedade), a PNEM consolida os anseios dos educadores de museus por instituições e processos museológicos com maior relevância social, voltados para a educação de seus públicos e em permanente diálogo com a sociedade.

Pautada nos princípios de promoção do acesso ao patrimônio salvaguardado pelos museus, a PNEM ressoa em seus princípios e diretrizes os mesmos ideais presentes na Política Nacional de Museus. (BRASIL, 2003). A existência de uma política de estado voltada a " $[$...] nortear a realização das práticas educacionais em instituições museológicas, fortalecer a dimensão educativa em todos os espaços do museu e subsidiar a atuação dos educadores." (INSTITUTO BRASILEIRO DE MUSEUS, 2017), reforça a possibilidade da existência de museus pautados na "[...] participação popular na 
REDES E ATIVISMO EM POLÍtiCAS PÚBLICAS: a construção da Política Nacional de Educação Museal (PNEM)

gestão do patrimônio, promoção do acesso ao patrimônio musealizado para todas as camadas da população, incentivo à musealização do patrimônio oriundo da diversidade cultural brasileira e à sustentabilidade dos processos museais." (MARTINS, 2011, p. 248).

É notável, portanto, perceber que em um país cujo patrimônio museal não é considerado pela maior parte da população como uma opção de acesso àcultura1, a existência de uma política específica para o fomento da educação museal. Vale ressaltar que o ineditismo da PNEM se estende, mundialmente, na medida em que não existem registros de políticas de educação museal em outros países2.

A partir desse contexto, surge o mote do presente artigo, que busca lançar luz sobre o processo de construção da PNEM, com especial atenção ao protagonismo dos profissionais da educação museal. A hipótese que se delineia, coloca no interesse e entusiasmo desses atores, organizados em redes e associações de classe, o protagonismo decisivo para a formulação da PNEM. Ao mesmo tempo profissionais da ponta, responsáveis pela concepção das ações educativas e pela recepção dos visitantes nos museus, os educadores museais são também os artífices da política, em um duplo papel de agentes de recontextualização pedagógica3 e produtores da prática educacional nos museus (MARTINS, 2011; MARTINS; MARANDINO, 2013).

Essa constatação, quando considerada sob o enfoque da produção das políticas públicas, indica uma instigante participação desses atores. Lipsky (1980), com seu olhar inaugural sobre os chamados burocratas de nível de rua (street level bureaucrats); aponta, ainda, para o fato de que a implementação modifica as políticas, dado que os atores da ponta não são os mesmos formuladores das políticas, traduzindo-as à sua maneira, em virtude dos enfrentamentos (coping) cotidianos provocados pelo lapso entre planejado e realidade.

A visão contemporânea ressalta o protagonismo estatal e a multiplicidade de atores na produção de políticas públicas, perspectiva que se complexifica com a participação dos atores em diferentes graus nas suas diferentes etapas, com restrição ou alargamento nas possibilidades de sua ação. A fase de implementação é vista como aquela em que ocorre uma ampliação na participação de atores em comparação à fase de formulação, cujo protagonismo estatal e de 
grupos preferenciais prevalece. (HOWLETT; RAMESH; PERL, 2013).

No caso da PNEM, o que se observa é a coincidência entre atores formuladores e implementadores. Sob a ótica deste artigo, tal fato deriva de um arranjo em rede, em que atores-chave lideram processos articuladores envolvendo sub-redes estaduais, atores locais e ocupação transitória de cargos estratégicos na estrutura estatal.

Tal constatação pode ser atribuída a processos específicos, de cuja descrição se propõe o presente artigo e cujo resultado pretende uma compreensão de como as relações são processadas nas redes, isto é, como são formadas as estratégias nas e pelas redes, acesso a recursos, articulações e alianças, enfim, sobre seu processo de gestão. (ANDRADE, 2006). Nesse enfoque, portanto, a rede é analisada como um mecanismo de poder liderado por empreendedores da política pública (policy entrepreneurs) - atores que desempenham papel de destaque na defesa das ideias relacionadas à definição dos problemas e na construção das soluções. (KINGDON, 1984).

A atuação da rede no processo de formulação da política se dá mediante dinâmica estabelecida nas relações entre atores estrategicamente posicionados, dentro e fora das instituições estatais, como servidores públicos de carreira, intelectuais, pesquisadores e técnicos da área cultural que eventualmente se alternam em postos chave mediante ocupação de cargos públicos comissionados no governo federal.

Como empreendedores de políticas públicas, participam e fomentam um movimento que se expressa no crescimento do setor desde a primeira metade dos anos 2000 , resultando em maiores investimentos públicos e políticas setoriais específicas, gerando um aumento quantitativo do próprio campo, refletido, por exemplo, na abertura de novas vagas para profissionais nas instituições museais.

Importante salientar, desde já, que "[...]a noção de redes de políticas públicas se contrapõe à percepção tradicional de que o governo pode ser compreendido como uma entidade independente e, em grande medida, acima do restante da sociedade." (CALMON; COSTA, 2013, p. 11). As ações tidas como oriundas da esfera estatal importam, seja pela sua envergadura enquanto instituição, mas, sobretudo, em decorrência da permeabilidade do governo federal cujo 
REDES E ATIVISMO EM POLÍtiCAS PÚBLICAS: a construção da Política Nacional de Educação Museal (PNEM)

trânsito de atores chave em suas estruturas propicia um empoderamento para este setor da área cultural.

Este artigo pretende ir além da constatação de que redes e multiplicidade de atores importam para a produção de políticas públicas, compreendendo interna e detalhadamente seus mecanismos e processos particulares, descortinando, assim, arranjos que contêm potencial explicativo sobre seu desempenho.

Constata-se que tal desempenho liga-se a um processo de acúmulo histórico que deriva num inédito patamar de atenção estatal para a área, e cujo ápice é relativamente recente, contexto produzido em boa medida pelos e no qual atuam esses atores-chaves, responsáveis pela ativação da rede - na sua formação e manutenção (KICKERT; KLIJN; KOPPENJAN, 1999; MCGUIRRE, 2003) - possuidores de um perfil profissional permeado pela militância em torno de uma causa, $o$ que dota este movimento em rede de características significativamente aglutinadoras, com uma visão comum para o setor que se espraia entre seus membros (condizentes com características a serem detalhadamente expostas no tópico quatro deste artigo).

Tal processo de construção de consensos e objetivos alcançados auxilia a compreender a potencialidade de redes de políticas públicas no que tange à sua organização, aspecto ligado ao tema da governança de redes de políticas públicas, permeando as relações estado-sociedade. Observa-se que os problemas envolvendo a ação coletiva, tais como a heterogeneidade de atores e sua coordenação, bem como as barreiras diversas que limitam a atuação de redes de políticas públicas (MCGUIRRE; AGRANOFF, 2011), encontram no caso estudado um exemplo de significativo sucesso. Nesse sentido, as contribuições a que se propõe esse trabalho reforçam-se pela constatação de Calmon e Costa $(2013$, p.18) que afirmam que, "[...] embora haja uma ampla bibliografia tratando de questões relacionadas à natureza $\mathrm{e}$ importância das redes de políticas públicas, existem poucos trabalhos voltados para a análise dos aspectos relacionados à governança dessas redes".

Além desta introdução, este artigo procura, na sessão seguinte, contextualizar a educação em museus no panorama das políticas públicas para o setor. A seguir, dedica-se a descrever o processo de formulação da PNEM. Antecedendo o tópico conclusão, apresenta uma análise dos processos e atores enfocados à luz de referenciais teóricos em governança de redes de políticas públicas. Este artigo se 
baseia em pesquisa documental e observação, sendo uma das autoras participante dos processos descritos.

\section{A EDUCAÇÃO MUSEAL NO CONTEXTO DAS POLÍTICAS PÚBLICAS MUSEAIS}

O relacionamento entre os museus e as práticas educacionais existe desde a origem dessas instituições, antes mesmo do surgimento dos museus modernos no século XIX. Os objetos coletados, classificados e estudados pelas equipes dos museus têm se constituído como fonte de conhecimento, ao se prestarem tanto à pesquisa quanto ao ensino (ABT, 2006), contribuindo inclusive para conformação das disciplinas científicas modernas como a História, a Geologia, a Paleontologia, a Biologia e a Antropologia. (LOPES, 1997).

Essa relação estreita entre acervos e produção de conhecimento foi acompanhada historicamente pela divulgação por meio de exposições, palestras, cursos e demonstrações públicas. Os serviços educativos propriamente ditos têm sua origem no século XIX, quando muitos museus europeus passam a receber o público escolar de forma mais frequente, ao mesmo tempo em que discursos sobre o aprendizado, a partir dos objetos, encontravam espaço nas chamadas pedagogias renovadas.

Ao longo do século XX o papel que as ações educacionais passaram a desempenhar nos museus cresce de forma inegável. Sob os auspícios de novas práticas museais, denominadas por muitos autores como uma nova museologia, o público, e suas necessidades, passaram a ser o foco das instituições museais, mais do que as coleções ou a pesquisa. Nesse cenário, as práticas de educação adquiriram grande importância, fazendo com que a função dos profissionais por elas responsáveis se expandisse além do papel de visitas guiadas para escolares e passasse, em muitas instituições, a englobar uma série de atividades relacionadas com o público, como concepção de exposições, treinamento de professores, estudos de público, ações comunitárias, administração do trabalho de voluntários e captação de recursos. (ROBERTS, 1997).

Essa situação, aparentemente favorável à diversificação e ampliação das práticas educacionais nos ambientes museais, não é, entretanto, consensual em todos os tipos de museu. A educação é vista, muitas vezes, como um dos aspectos polêmicos da instituição museal, por ser derivada de um movimento interno aos museus em 
REDES E ATIVISMO EM POLÍtiCAS PÚBLICAS: a construção da Política Nacional de Educação Museal (PNEM)

que as funções de coleta e pesquisa, que historicamente constituíram essas instituições, se contrapõem àquelas, mais recentemente valorizadas, de atuação junto aos diferentes públicos. (VALENTE, 2008).

Esse ponto de vista sobre o desprestígio da educação nos museus é corroborado por Seibel-Machado (2009) e Martins (2013) e traz para o centro do debate a dimensão e o papel que a educação deve assumir em uma instituição museal. Esse debate se faz presente na principal política pública da área: a Política Nacional de Museus (PNM), base do Estatuto de Museus a Lei $n^{0} 11.904 / 2009$, lei que rege a área no Brasil. O Estatuto de Museus não somente define o que são os museus, como estabelece sua forma de atuação no País.

Especificamente sobre a educação, o Estatuto é bastante sintético, contando apenas com um item específico que delimita para os museus " [...] promover ações educativas, fundamentadas no respeito à diversidade cultural e na participação comunitária, contribuindo para ampliar o acesso da sociedade às manifestações culturais e ao patrimônio material e imaterial da Nação." (BRASIL, 2009). Nota-se que dentre essas diretrizes, é possível inferir um papel de destaque às ações de extroversão museal, presumindo que será por meio delas que se fará esse contato direto com a população. Essa tendência, presente nos textos legais, é retrato de um movimento histórico de pressão em favor dos museus e, mais notadamente, pano de fundo de lutas que buscam um novo patamar para a educação museal.

É importante considerar que a criação de um instrumento de regulação é algo extremamente recente - e inédito - no contexto governamental da administração cultural nacional. É a partir da gestão iniciada em $2003^{4}$ que começam as transformações que levarão à criação, em 2009, do Ibram - Instituto Brasileiro de Museus, órgão responsável pela gestão dos museus federais, pela PNM e pela melhoria dos serviços no setor. Anteriormente à criação do Ibram existia o Departamento de Museus (DEMU), vinculado ao Instituto de Patrimônio histórico e artístico nacional (Iphan).

Com a expansão das atribuições do DEMU e o crescimento e fortalecimento da área museal, em 2009 foi criado o Instituto Brasileiro de Museus. Esses fatos foram precedidos de uma intensa movimentação na área de museus nacionais, iniciada em 2003, quando da ascensão ao poder de uma nova equipe e do início das discussões para a redação coletiva da Política Nacional de Museus (BRASIL, 2003). 
A redação da PNM contou com a participação de "[...] entidades vinculadas à Museologia, meio universitário, profissionais da área e secretaria estaduais e municipais de cultura." (BRASIL, 2003, p. 7). Destaca-se na conformação da Política Nacional de Museus o princípio orientador " [...] desenvolvimento de processos educacionais para o respeito à diferença e à diversidade cultural do povo brasileiro frente aos procedimentos políticos de homogeneização decorrentes da globalização." (BRASIL, 2003, p. 9), por sua relação explícita com a questão educacional.

Nesse sentido, é importante ressaltar que a tônica presente tanto nos princípios, quanto nos artigos da PNM, está intimamente ligada aos conceitos de participação popular na gestão do patrimônio, promoção do acesso ao patrimônio musealizado para todas as camadas da população, incentivo à musealização do patrimônio oriundo da diversidade cultural brasileira e à sustentabilidade dos processos museais. Todos esses aspectos traduzem um panorama museal de abertura e participação dos diversos públicos, que têm estreita relação com a ampliação do papel educacional desempenhado pelas instituições museológicas.

Percebe-se, a partir do exposto, que a área cultural, arena institucional na qual se posicionam os museus nacionais, está em plena efervescência no que tange à estruturação de políticas públicas oficiais. Desde o lançamento da PNM até a promulgação do Estatuto de Museus, todas as ações realizadas no período de 2003 a 2010 buscam a maior estruturação da área e a maior presença do estado na efetivação das políticas públicas do setor.

Nota-se a paulatina estruturação de um discurso oficial sobre a área de museus que busca regular os diversos aspectos da prática, tanto no nível institucional quanto no nível das próprias esferas de poder locais (nos níveis público - estadual, municipal e regional - e privado).

Essa regulação vem, de certa forma, ocupar um vazio em termos de políticas públicas oficiais para a área. Poucas são as instâncias de poder - sejam públicas ou privadas - que, ao possuírem uma instituição museal, têm políticas oficialmente definidas para elas. O histórico da área museal é mais pautado por ausências do que por presenças, unindo-se ao já conhecido coro de vozes que alertam sobre falta de políticas que resguardem a memória - material e imaterial - nacionais. Os museus, enquanto parte importante dessas 
REDES E ATIVISMO EM POLÍtiCAS PÚBLICAS: a construção da Política Nacional de Educação Museal (PNEM)

instituições guardiãs da memória nacional, não são privilegiados em nenhum aspecto e partilham da ausência crônica de investimento que pautam a área cultural no Brasil. (BRUNO, 1995; VALENTE, 1995).

Os contornos assumidos por essa regulação, no âmbito federal, apontam para a construção de uma política de caráter indutivo. Se a princípio o formato era pautado pela adesão espontânea - como no caso dos primeiros editais para Modernização dos Museus, que não exigiam nenhum tipo de contrapartida de adequação institucional - com a promulgação do Estatuto inicia-se uma perspectiva de maior adequação dos museus às diretrizes do Ibram.

No caso da educação praticada nos museus, percebe-se um movimento de mão dupla. Ao mesmo tempo que, como dito, a educação parece ser uma das propulsoras das diretrizes presentes na Política Nacional de Museus - principalmente no que se refere à participação comunitária e ao fomento à diversidade cultural - ela não aparece com funções especificamente definidas no Estatuto de Museus, nem é privilegiada de forma específica nos editais de fomento do Ibram.

Observa-se, portanto, um movimento mais amplo, de configuração dos museus enquanto instituições nos quais as premissas educacionais estão imiscuídas em todas as ações. Para o Ibram os museus têm funções relativas ao desenvolvimento e à integração nacional. Temas como diversidade cultural, representação social, acessibilidade e mesmo desenvolvimento econômico fazem parte da pauta museal governamental. A educação é apontada, juntamente com outras funções museais, como um dos motores para o alcance desses objetivos.

\section{O PROCESSO DE FORMULAÇÃO DA PNEM}

As origens da discussão da PNEM estão no I Encontro de Educadores dos Museus do Ibram, realizado no Museu Imperial (Petrópolis-RJ), em 2010. Nesse encontro se reuniram não somente os educadores dos museus do Instituto Brasileiro de Museus (Ibram), mas também profissionais e pesquisadores da educação museal. Como resultado, foi publicada a Carta de Petrópolis (INSTITUTO BRASILEIRO DE MUSEUS, 2010), na qual foram apresentados os subsídios para a construção de uma Política Nacional de Educação Museal. Tendo a Política Nacional de Museus, o Plano Nacional 
Setorial de Museus e o Estatuto de Museus como referência, o documento apontou diretrizes temáticas para a construção da PNEM, que em 2012 foram transformadas nos Grupos de Trabalho ${ }^{5}$ do blog do Programa Nacional de Educação Museal (Disponível em:<https:// pnem.museus.gov.br >). O blog ficou aberto para as discussões e contribuições até abril de 2013. Cada Grupo de Trabalho era coordenado por um servidor do Ibram, alguns deles diretores de instituições, mas a maior parte era de educadores atuantes nos museus federais.

As contribuições recebidas no blog foram posteriormente sistematizadas e analisadas pelos coordenadores dos GTs e compuseram o Documento preliminar do Programa Nacional de Educação Museal, publicado em outubro de 2013. Já nesse documento se instalava a polêmica política versus programa. O texto de apoio 1 Por uma política nacional de educação em museus (MARTINS, 2013), realizado a convite da articuladora do GT Redes e Parcerias para uma pesquisadora da temática das políticas públicas de educação museal, era o resultado do desejo dos coordenadores dos GTs em referendarem as discussões e dilemas vividos de 2010 até aquele momento pelos formuladores da PNEM.

Dois aspectos principais eram considerados problemáticos pelos coordenadores dos GTs. O primeiro era relativo à qualidade da discussão empreendida pelos participantes do blog, que contou com 708 cadastrados entre educadores de museus, pesquisadores da temática, profissionais de museus e professores da educação básica. Suas discussões resultaram em 83 tópicos de debates com 598 comentários que, em parte, refletiam um grau de maturidade ainda pouco aprofundado sobre as especificidades da educação museal no panorama nacional. Temas já superados pela pesquisa da área, como museus voltados para a educação escolar, ou conceitos pouco consolidados, como mediação versus educação, foram alvo de intensos debates no blog.

Outro aspecto importante foi a já mencionada polêmica entre programa e política. Sobre essa polêmica, o coordenador do GT Perspectivas Conceituais aponta que:

É desse modo que se destacam aqui as discussões em torno do uso dos termos "política" e "programa", postulando a necessidade de construção e constituição de uma "Política Nacional de Educação Museal" no Brasil, sem prejuízo às demais disposições legais já existentes ou em complementação a elas. Um Programa, conforme 
REDES E ATIVISMO EM POLÍtICAS PÚBLICAS: a construção da Política Nacional de Educação Museal (PNEM)

apontamentos do debate, pode se restringir aos limites temporais de um determinado mandato governamental, ao passo que uma Política carrega em si a possibilidade e determinação legal de transcender a estes limites. (SOARES, 2013, p. 9).

O texto de apoio corroborava essa postura, argumentando que a formulação de uma política, com uma participação expressiva dos próprios educadores de museus, trazia a possibilidade decisiva de implementação de ações em prol da educação nos museus nacionais, contribuindo de forma efetiva para a propalada valorização do patrimônio museal perante a sociedade brasileira, estabelecida pelo Estatuto de Museus.

Após a construção do Documento Preliminar, a proposta de continuidade para a formulação da PNEM era a realização de encontros regionais presenciais, seguido do I Encontro Nacional da PNEM a ser realizado no $6^{\circ}$. Fórum Nacional de Museus. O objetivo dos encontros regionais era promover a discussão do Documento Preliminar e coletar sugestões para sua alteração. Tanto os coordenadores dos GTs quanto a própria direção da Coordenação de Museologia Social e Educação (Comuse), órgão do Ibram diretamente responsável pela PNEM, consideravam que o Documento Preliminar ainda estava longe de se constituir como texto de uma política pública.

Apesar de sua estrutura estar organizada em diretrizes, estratégias e ações, seguindo formato do Plano Nacional Setorial de Museus (BRASIL, 2010), e ter passado por uma revisão dos coordenadores dos GTs, o texto ainda era o resultado das discussões empreendidas no blog. Inconsistências, repetições, redundâncias e aspectos que não eram pertinentes a uma política de educação museal ainda estavam presentes.

Os encontros regionais foram realizados em 2014, contabilizando 23 reuniões em 13 unidades da federação ${ }^{6}$. Foram fundamentais, para sua realização, as Redes de Educadores de Museus (REMs), em parceria com articuladores locais e com os educadores do Ibram. Tanto as Redes como os articuladores atuaram de forma voluntária, estimulados pelos coordenadores dos GTs, que eram os servidores do Ibram diretamente ligados à PNEM. Um aspecto que se evidencia foi a não realização dos debates em todos os estados, além de ausência de mecanismos de difusão apropriados para o amplo debate do Documento Preliminar. 
Os encontros regionais resultaram em mais de 400 sugestões de alteração do Documento Preliminar, entre acréscimos, supressões e alterações na sua estrutura. $\mathrm{O}$ documento não permitia uma discussão coletiva, dado a sua enormidade. Entretanto, por falta de tempo hábil e verbas, parte dele foi levada para discussão da forma que se encontrava ${ }^{7}$, no I Encontro Nacional do PNEM, durante o $6^{\circ}$. Fórum Nacional de Museus (Belém - PA). A Comuse financiou a presença dos articuladores regionais durante o Encontro.

Estes, juntamente com os coordenadores dos GTs, propuseram a discussão e sistematização apenas das diretrizes do GT de Perspectivas Conceituais, que traziam, justamente, alguns dos conceitos basilares para a constituição da Política. Após a discussão e votação em assembleia, foram aprovados os denominados Princípios da PNEM, juntamente com a Carta de Belém, que apontava a necessidade de realização do II Encontro Nacional da PNEM para a votação do texto final da Política Nacional de Educação Museal, ainda no segundo semestre de 2015.

Foi somente em 2017 que a PNEM foi retomada. No período de novembro de 2014, data do I Encontro da PNEM, até a realização do II Encontro da PNEM, durante o $7^{\circ}$ Fórum Nacional de Museus (Porto Alegre - RS) em 2017, diversas turbulências políticas sacudiram o País. Nesse período, a presidência do Ibram mudou algumas vezes, e muitos dos programas existentes foram paralisados ou deixaram de existir. Em abril de 2014, as REMs enviaram uma carta ao então presidente do Ibram, solicitando a retomada do processo de formulação da PNEM, o que não aconteceu.

Com uma nova mudança da presidência do Ibram, em 2016, o pedido foi reiterado e, dessa vez, atendido. Essa carta também contou com a assinatura da presidente do Comitê de Educação e Ação Cultural do Conselho Internacional de Museus (Ceca-Icom), cargo ocupado por uma brasileira, e da coordenadora brasileira do Ceca. Elas fazem parte de uma rede de contatos que envolve os coordenadores dos GTs da PNEM, em especial a coordenadora do GT Redes e Parcerias, uma das principais entusiastas de todo o processo.

Para retomar a discussão da PNEM era necessário dar conta da sistematização do documento resultante dos encontros regionais. Como já explicitado, o referido documento contava com mais de 400 sugestões de modificação, e era pródigo em repetições, inconsistências e problemas de redação. Para dar conta desse trabalho, 
REDES E ATIVISMO EM POLÍtiCAS PÚBLICAS: a construção da Política Nacional de Educação Museal (PNEM)

a tempo de ser apresentado no $7^{\circ}$ Fórum Nacional de Museus, foi contratada uma consultora, que vinha participando do processo desde o Documento Preliminar, e, também, atuava como articuladora regional em São Paulo. O resultado desse esforço foi o texto base para a discussão durante o II Encontro Nacional da PNEM, realizado em Porto Alegre, no $7^{\circ}$ Fórum Nacional de Museus.

O II Encontro resultou na finalização do texto da Política Nacional de Educação Museal e se constitui como um marco para a área. Participaram da assembleia, viabilizados pelo Ibram, representantes das REMs de diferentes estados, além de diversos articuladores regionais. Publicada como portaria do Ibram (Portaria $n^{\circ} 422$, de 30 de novembro de 2017) a PNEM tem agora o desafio de ser implantada nos museus. Os educadores de museus, participantes ativos do processo de formulação, têm agora a implementação da Política condicionada pelos aspectos estruturais das instituições nas quais atuam.

Sob essa perspectiva, se os anseios de formuladores e implementadores se confundem na figura desses atores - algo incomum em se tratando de processos de construção de políticas públicas, cuja literatura enfatiza as assimetrias - as condições materiais nas quais se inserem suas práticas serão foco de tensão pelas possibilidades de enfrentamento e necessária adaptação do planejado à realidade. Nesse sentido, não se trataria de adaptar e modificar a política, aspecto comumente apontado pela literatura da área sobre os lapsos entre formuladores e implementadores, mas de ter na implementação mais um momento de luta e construção de estratégias para a efetivação de uma visão de mundo sobre a educação em museus.

\section{ASPECTOS DA GOVERNANÇA DE REDES DE POLÍTICAS PÚBLICAS}

A racionalidade negociada que caracteriza as redes, cuja distribuição de poder multicêntrica contrasta com instituições hierárquicas, ao mesmo tempo que se mostram potencialmente estratégicas para o enfrentamento de problemas públicos, trazem uma série de desafios, sobretudo em contextos de fragilidade democrática, com baixa capacidade de organização social. Trata-se, portanto, de processos que envolvem exercício de aprendizagem coletiva, desenvolvimento de confiança mútua entre atores, de participação em proces- 
sos decisórios, transparência, entre outros, aspectos circunspectos, em última instância, ao chamado capital social. (PUTNAM, 1996).

Sob essa perspectiva, a definição de um problema público, de interesse comum, não se constitui em algo simples, ao passo que a formulação de uma política pública resulta de um processo político complexo, cujas dinâmicas envolvendo interesses de atores sociais não raro geram desfechos de difícil antecipação. Processos sociais como esses,

[...] envolvem atores distintos, com preferências heterogêneas, com recursos de poder distintos e assimetricamente distribuídos, e que precisam resolver seus problemas de coordenação, cooperação e comunicação. Além disso, como ressaltam vários autores, esses problemas são tratados em um ambiente marcado pela ambiguidade e incerteza, o que torna ainda mais difícil articular a ação coletiva. (CALMON; COSTA, 2013, p.13).

Vencer esses desafios por meio de uma ação coletiva organizada, atingindo objetivos consensuados, pode ser considerado, portanto, uma enorme vitória no campo social em sociedades como a brasileira. Elementos que ajudam a compreender o desfecho bem sucedido da PNEM é o objetivo deste item. Para isso, buscou-se na literatura sobre governança de redes de políticas públicas reflexões, que, colocadas frente ao material dos tópicos anteriores, visam iluminar o caso estudado.

McGuire e Agranoff (2003, p. 4) apontam que redes de políticas públicas são "[...] arrangements to solve problems that cannot be solved, or solved easily, by using single organizations". Essa visão é complementada pelas contribuições de Calmon e Costa (2013, p. 15), que afunilam o foco atentando para o fato que redes de políticas públicas envolvem um conjunto de relacionamentos entre atores heterogêneos e interdependentes, voltados para atuação em um mesmo subsistema de políticas públicas, sob uma "[...] estrutura de governança constituída por regras formais, informais e maneiras e formas de interpretá-las e implementá-las".

No caso da PNEM, nota-se a existência de uma rede atuante na construção dessa política pública, sendo possível a identificação de diferentes atores interessados, interdependentes e que compartilham visões envolvendo práticas e ideias. Ao longo da estruturação do processo descrito no tópico anterior, identifica-se a existência de entusiastas que aderem ao processo de formulação da PNEM, seja 
REDES E ATIVISMO EM POLÍtiCAS PÚBLICAS: a construção da Política Nacional de Educação Museal (PNEM)

de forma espontânea ou estimulados por atores-chaves responsáveis pela ativação da rede.

Além dos servidores públicos, locados nos museus do Ibram (diretores e educadores que atuaram como coordenadores dos GTs do blog da PNEM), sobressaem os articuladores regionais e a própria figura das Redes de Educadores de Museus (REMs). Sobre as REMs, é importante caracterizar que seu formato é distinto de acordo com o local, mas, de maneira geral, são associações não formalizadas, de educadores que atuam em museus e exposições temporárias, pesquisadores e interessados no tema. Tem um papel fundamental na articulação de atores e ideias ligadas à educação museal, atuando de forma efetiva para a consolidação desse campo profissional e intelectual. (MARTINS, 2011).

Ao abordarem perspectivas teóricas sobre a formulação de políticas públicas, Calmon e Costa (2013), num esforço de sistematização, aprofundam a compreensão sobre a perspectiva da governança de redes. Tendo como mote a questão "[...] que funções fundamentais deveriam ser exercidas na gestão de redes de políticas públicas?", os autores, remetendo-se aos estudos de Kickert e Koppenjan (1999) e McGuire (2003) "[...] apontam para um conjunto de estratégias, e não especificamente de funções, que deveriam ser exercidas na gestão de redes de políticas públicas." (CALMON; COSTA, 2013, p. 19).

A exemplo da característica ativação, sob a ótica deste artigo, entende-se que os referenciais sistematizados por Calmon e Costa (2013) sejam úteis para uma melhor compreensão dos processos enfocados na estruturação da PNEM. A gestão de redes é apresentada por esses autores a partir da analogia de um jogo estratégico que envolve as funções a) ativação da rede; b) enquadramento das relações; c) intermediação; d) facilitação e criação de consenso; e) e mediação e arbitragem.

A (a) ativação é tida como primordial entre as funções de administração da rede em virtude de laços potenciais que nem sempre estão adequadamente ativados, numa visão de reversão da subotimização de interações e de promoção de engajamento nos problemas coletivos. A função ativação envolve identificar e incorporar pessoas e organizações implicadas no alcance dos objetivos estabelecidos, avaliando características como recursos, conhecimentos e habilidades dos membros a serem mobilizados. 
A (b) função enquadramento das relações se desenrola após a ativação e se liga à fase formativa de uma rede ou quando ela tem sua capacidade reduzida. Visa, assim, o desenvolvimento de condições para interação, com a facilitação de acordos, definição de arenas e procedimentos para interação dos atores. São elas atribuições da liderança da rede, bem como cultivar, desenvolver e disseminar as bases que orientam esse enquadramento. Como se trata da mobilização de atores heterogêneos, sendo provável o surgimento de conflitos, torna-se "[...] necessário desenvolver um quadro de referência para interação que estabeleça bases institucionais para a cooperação [contando, inclusive, com a possibilidade de] formalização de um acordo, termo de compromisso ou até mesmo um contrato." (CALMON; COSTA, 2013, p. 21).

A (c) função intermediação liga-se à constatação do potencial subjacente à força dos laços fracos e à presença de vazios estruturais. Tal constatação foi explorada nos estudos da Nova Sociologia Econômica, em que Granovetter (1973) inova ao abordar a força dos laços fracos, em contraposição a redes fechadas nas quais a redundância das relações entre atores unidos por laços fortes propicia menos oportunidades de interações, produzindo, portanto, menos efetividade. Vislumbra-se, assim, a potencialidade de intermediários explorarem e apoiarem essas articulações, presentes em um ambiente no qual,

[...] prevalecem organizações "fracamente acopladas", com grande fragmentação e multiplicidade de atores heterogêneos, sendo que "vazios estruturais" e "laços fracos" são esperados. A importância da intermediação reside no fato de que ela resulta na reunião de diferentes recursos, informações, ideias e soluções que estão presentes na rede, mas que podem estar dispostos em "cliques" distintos, havendo um "vazio estrutural" entre esses elementos. (CALMON; COSTA, 2013, p. 21).

Nesses processos, a necessária sincronização é o mote para o surgimento dos empreendedores de políticas públicas, atores que investem tempo e recursos em iniciativas nesse campo. "Esses empreendedores não apenas encaminham soluções, mas também propõem novos problemas e, mais importante, articulam outros atores a coordenarem suas ações." (CALMON; COSTA, 2013, p. 21).

A (d) função facilitação e criação de consenso visa criar condições para uma interação favorável e produtiva. Tal medida se ancora no fato que a relação entre atores heterogêneos é quase sem- 
REDES E ATIVISMO EM POLÍtiCAS PÚBLICAS: a construção da Política Nacional de Educação Museal (PNEM)

pre marcada por dificuldades de comunicação e por alto risco de conflitos, justificando a existência de um facilitador que "[...] organize a interação entre os atores, auxilie na comunicação, incentive a compreensão das diferenças de identidades e valores e viabilize a formação de consenso". (CALMON; COSTA, 2013, p. 21).

Tal função envolve tanto aspectos práticos como organização de encontros, reuniões, gestão da informação e comunicação interna e externa, mas também o "[...] monitoramento da qualidade do diá$\log$ e a tradução e adaptação de conceitos, a promoção de valores compartilhados, a redução da complexidade e da incerteza nos relacionamentos e outras iniciativas que possam promover o entendimento mútuo e a formação de consenso." (CALMON; COSTA, 2013, p. 22).

A quinta função, (e) mediação e arbitragem, assemelha-se à função criação e consenso. No entanto, este se aplica após o surgimento de conflitos, enquanto o anterior objetiva prevenir, isto é, atuar antes que o conflito se instale. O papel intermediário cabe geralmente à direção da rede, figura externa, sendo a resolução final do conflito responsabilidade cabível às partes diretamente envolvidas.

Uma dimensão adicional sistematizada a partir de McGuirre (2003), por Calmon e Costa (2013), se liga ao tema do ambiente das redes de políticas públicas e sua importância. Esses aspectos são também úteis aos propósitos deste artigo. McGuire (2003) aponta cinco características básicas do ambiente em que se insere uma rede e que podem afetar o seu desempenho.

A primeira delas refere-se ao (1) Consenso sobre os objetivos: uma rede com tal característica tende a ser mais efetiva do que uma rede onde há ainda necessidade de definir e pactuar objetivos. "Em uma rede com objetivos bem definidos e consensuais, os seus gestores dedicarão mais tempo à ativação da rede, ao enquadramento e à intermediação [...] onde não são, ou ainda não foram pactuados, seus gestores dedicarão mais tempo à facilitação, mediação e arbitragem." (CALMON; COSTA, 2013, p. 23). A segunda característica refere-se à (2) Distribuição de recursos: a participação na rede deriva da quantidade de recursos - distribuição da autoridade legal, recursos materiais, informação, expertise e experiência disponíveis - para cada ator. Recursos bem distribuídos entre uma vasta gama de atores resulta em uma rede vasta. Recursos concentrados em poucos atores, a rede tende a ser mais restrita. "Gestores de rede 
experientes sabem como os recursos são distribuídos e mobilizam esses recursos no momento mais adequado para a geração dos resultados preconizados pelo grupo." (CALMON; COSTA, 2013, p. 23). (3) Apoio político: característica fundamental para o bom funcionamento da rede; sua inexistência consome grande parte do esforço de gestão para sua obtenção, muitas vezes em detrimento do exercício das outras funções. (4) Relacionamentos: confiança e capital social são também essenciais para "[...] o bom funcionamento de uma rede. Se os membros já interagiram no passado, conhecem bem um ao outro, então menos tempo precisa ser dedicado ao enquadramento e à intermediação do que numa rede formada por estranhos ou pessoas que interagem pela primeira vez." (CALMON; COSTA, 2013, p. 23). A quinta característica, (5) Orientação em relação às políticas públicas, adverte que,

\begin{abstract}
Se há um paradigma de políticas públicas compartilhado entre todos os atores e esse paradigma indica metas, objetivos, prioridades e instrumento, então o gestor da rede necessita gastar menos energia na formação de consenso sobre esses elementos fundamentais das políticas públicas. Por outro lado, se os membros da rede adotam diferentes paradigmas para orientar sua atuação, então o potencial de mobilização é reduzido e o risco de ocorrerem conflitos cresce bastante (CALMON; COSTA, 2013, p. 24).
\end{abstract}

Como pontuam Calmon e Costa (2013, p. 25), as características e funções básicas descritas voltam-se para o gerir os vários aspectos de uma rede, considerando-se também aspectos relacionados ao ambiente no qual uma rede está inserida. Se por um lado tais elementos relacionam-se à capacidade de mobilizar atores na resolução dos problemas enfrentados pela coletividade, por outro, referem-se à capacidade da rede de resolver os problemas de ação coletiva, especialmente aqueles voltados para a cooperação, coordenação e comunicação entre os envolvidos, gerando os resultados esperados e sustentando essas ações ao longo do tempo.

Por fim, os autores apontam dimensões úteis para diagnosticar a capacidade de governança das redes de políticas públicas: I) capital social (entre outros aspectos, existência de valores comuns aos diversos membros da rede); II) institucionalização (espaços, rotinas e práticas sociais compartilhadas entre os atores da rede); III) sustentabilidade (capacidade de realizar ações continuas e de longa duração); IV) estrutura e instrumentos de coordenação (órgãos colegiados com ampla participação dos atores e legitimidade da co- 
REDES E ATIVISMO EM POLÍtiCAS PÚBLICAS: a construção da Política Nacional de Educação Museal (PNEM)

ordenação entre os membros da rede); V) comunicação (o grau de governança de uma rede depende da qualidade das interações entre os atores; a boa comunicação entre eles implica o intercâmbio de informações e a existência de sistemas formais e informais de consultas mútuas); e VI) informação e análise (planejamento e a implementação das ações demandam um fluxo de informações confiáveis; o grau de governança de uma rede de políticas públicas depende da qualidade e confiabilidade das informações disseminadas entre os atores).

A partir da literatura enfocada, percebe-se que o processo da PNEM espelha diversos aspectos trazidos pelos autores citados. Como já mencionado, o papel central de ativação da rede, cumprido pelos atores-chave, aparece incisivamente nesse movimento. Se isso não sobressai necessariamente de maneira direta na descrição desses processos, as funções de enquadramento das relações (que amplia a capacidade da rede e cria as condições para interação, com suas arenas e procedimentos), intermediação (reunião de diferentes recursos, informações, ideias e soluções muitas vezes dispersas por laços fracos), facilitação (criação de consenso visa criar condições para uma interação favorável e produtiva) e mediação e arbitragem (resolução de conflitos), isto é, funções ligadas às dinâmicas de uma rede já instalada e em funcionamento, sobressaem no caso do processo envolvendo a construção da PNEM. Nesse processo, múltiplos e heterogêneos atores interdependentes trabalham coordenadamente em prol de objetivos comuns consolidados no texto da Política. São, portanto, decorrentes de uma intencionalidade de ativação, cuja manutenção e expansão da rede se realizam.

Da mesma forma, aspectos relativos ao ambiente em que se insere uma rede e que podem afetar seu desempenho, como o consenso sobre os objetivos, a distribuição de recursos, apoio politico, relacionamentos e orientação em relação às políticas públicas, chamam a atenção quando se analisa a PNEN pelo cumprimento dos preceitos apontados por essa literatura.

Tal quadro se completa pelas características voltadas para diagnosticar a capacidade de governança das redes de políticas públicas, como os valores comuns (capital social); a institucionalização, refletida nos mecanismos de gestão, nas múltiplas instâncias de participação dos atores e no próprio produto final, a PNEM; na sustentabilidade, pelo movimento que se fortalece enquanto rede pe- 
los êxitos obtidos; e pelos demais aspectos relativos à mobilização em prol da gestão (instrumentos, estruturas, comunicação, dados, informações).

Aspectos pontuais poderiam ser aqui adicionalmente elencados a título de ilustrar características específicas que enfatizam essa compreensão - tais como a distribuição de recursos escassos entre atores a fim de potencializar a rede; as ações de formação de espaços coletivos de construção processual da política; os múltiplos e recorrentes eventos de diferentes formatos, visando reunir e potencializar o movimento em rede; as mobilizações do aparato estatal via ocupação de cargos estratégicos; a capilaridade e coordenação alcançadas etc. - mas entende-se que esse cotejamento se evidencie através das descrições detalhadas apresentadas anteriormente e os referenciais ora apresentados de governança de redes de políticas públicas.

Por fim, mas não menos importante, todo esse quadro de similaridades entre o caso exposto e a literatura, acrescido do desempenho da rede analisada, não deixa de ser intrigante. Sem desconsiderar o sentido prescritivo dos referenciais de Kickert e Koppenjan (1999) e McGuire (2003), chama a atenção o caráter performático dos processos enfocados, isto é, quando a realidade imita a teoria e a partir dela se estrutura.

\section{CONCLUSÃO}

Este artigo procura contribuir para a análise de aspectos relacionados à governança de redes de políticas públicas, e, mais especificamente, como apontado anteriormente, um campo carente, no que tange à contribuições, via estudos empíricos, que detalhem processos internos no funcionamento desses arranjos na área cultural. Procura, dessa forma, contribuir com o registro e análise de um processo histórico específico envolvendo uma política pública do campo cultural.

O detalhamento da construção da PNEM procurou evidenciar a complexidade e o empenho de atores em torno de um arranjo social envolvendo múltiplos atores distribuídos pelo território, interdependentes e articulados em redes.

A literatura de governança de redes de políticas públicas auxilia numa melhor compreensão sobre os aspectos descritos, que não se evidenciam naturalmente. Isso remonta ao fato de que, se por um 
REDES E ATIVISMO EM POLÍtiCAS PÚBLICAS: a construção da Política Nacional de Educação Museal (PNEM)

lado, as redes são objeto de análise, não obstante são também uma categoria conceitual e um instrumento analítico.

O caso da PNEM se mostra fecundo para iluminar processos envolvendo políticas públicas, cujo emaranhado de relações coordenadas culmina com a inusitada coincidência entre atores formuladores e implementadores, abrindo margem para reflexão sobre a identidade entre visões, agência e dependência estrutural. Como apontado, enquanto o primeiro aspecto parece avançar sobre um dilema tradicional indicado desde a obra seminal de Lipsky (1980), o segundo fator adiciona um elemento que relativiza o campo das mobilizações e ideias em face dos recursos nos processos de implementação de políticas públicas.

\section{REFERÊNCIAS}

ABT, J. The origins of the public museum. In: MACDONALD, S. A companion to museum studies. Carlton (Australia): Blackwell, 2006. p. 115-134.

ANDRADE, J. A. Redes de atores: uma nova forma de gestão das políticas públicas no Brasil? Gestão e Regionalidade, São Caetano do Sul, v. 22, n. 64, 2006.

BERNSTEIN, B. A estruturação do discurso pedagógico: classe, códigos e controle. Petrópolis, RJ: Vozes, 1996.

BRASIL. Casa Civil. Lei n ${ }^{\circ} 11.904$, de 14 de janeiro de 2009. Institui o Estatuto de Museus e dá outras providências. Brasília, DF, 2009.

Disponível em:<http://www.planalto.gov.br/ccivil_03/_Ato20072010/2009/Lei/L11904.htm>. Acesso em: $12 \mathrm{dez} . \overline{201} \overline{0}$.

Ministério da Cultura. Instituto Brasileiro de Museus. Plano Nacional Setorial de Museus: uma agenda política para os próximos 10 anos. Brasília, DF, 2010.

Brasília, $\overline{D F}$ maio 2003.

Política Nacional de Museus. Memória e cidadania.

BRUNO, M. C. O. Musealização da arqueologia: um estudo de modelos para o Projeto Paranapanema. 1995. Tese (Doutorado) Museu de Arqueologia e Etnologia, Universidade de São Paulo, São Paulo, 1995.

CALMON, P.; COSTA, A. T. M. Redes e Governança das Políticas Públicas. RP3-Revista de Pesquisa em Políticas Públicas, n. 1, 2013. 
GRANOVETTER, M. The Strength of Weak Ties. American Journal of Sociology, Chicago, v. 78, n. 6, p. 1360-1380, may 1973.

HOOPER-GREENHILL, E. Writing a museum education policy. Leicester: Department of Museum Studies, 1991. Disponível em: $<$ https://members.museumsontario.ca/sites/default/files/members/ EileanHooperGreenhillEducationPolicy_0.pdf $>$. Acesso em 15 jun. 2017.

HOWLETT, M.; RAMESH, M.; PERL, A. Política Pública: seus ciclos e subsistemas - uma análise de políticas públicas a partir das relações Estado e Sociedade. Rio de Janeiro: Elsevier, 2013.

INSTITUTO BRASILEIRO DE MUSEUS. Política Nacional de Educação Museal - PNEM. Brasília, DF, 2013. Disponível em: <https:// www.museus.gov.br/wp-content/uploads/2017/06/Documento-FinalPNEM1.pdf $>$. Acesso em 02 jan. 2018.

KICKERT, W.; KLIJN, E.; KOPPENJAN, J. Introduction: a management perspective on policy networks. In: KICKERT, W. J.; KLIJN, E.-H.; KOPPENJAN, J. F. Managing Complex Networks. London: Sage Publications, 1999. p. 1-13.

; KOPPENJAN, J. Public management and network management: an overview. In: KICKERT, W.; KLIJN, E.-H.; KOPPENJAN, J. Managing Complex Networks. London: Sage Publica tions, 1999. p. 35-61.

KINGDON, J. Agendas, alternatives, and public policies. New York: Harper Collins, 1984.

LIPSKY, M. Street-Level Bureaucracy: dilemmas of the individual in public services. New York: Russell Sage Foundation, 1980.

LOPES, M. M. O Brasil descobre a pesquisa científica: os museus e as ciências naturais no século XIX. São Paulo: Hucitec, 1997.

MARTINS, L. C. A constituição da educação em museus: o funcionamento do dispositivo pedagógico museal por meio de um estudo comparativo entre museus de artes plásticas, ciências humanas e ciência e tecnologia. 2011. Tese (Doutorado) - Faculdade de Educação, Universidade de São Paulo, São Paulo, 2011.

. Por uma política Nacional de Educação Museal. In: INSTITUTO BRASILEIRO DE MUSEUS. Documento preliminar da Política Nacional de Educação Museal. Brasília: Ibram, 2013.

; MARANDINO, M. Políticas de financiamento da educação em museus: a constituição das ações educacionais em museus de artes 
REDES E ATIVISMO EM POLÍtICAS PÚBLICAS: a construção da Política Nacional de Educação Museal (PNEM)

plásticas, ciências humanas e ciência e tecnologia. Ensino Em ReVista, Urbelândia, v. 20, n. 1, p. 57-68, jan./jun. 2013.

MCGUIRE, M. Managing networks: propositions on what managers do and why they do it. Public Administration Review, ano 62, n. 5, p. 599-609, 2003.

; AGRANOFF, R. The limitations of public management networks. Public Administration, [S. 1.], v. 89, p. 265-284, 2011.

MUSEUMS AND GALLERIES COMMISSION. Educação em Museus. São Paulo: Editora da Universidade de São Paulo; Fundação Vitae, 2001. (Sárie Museologia, 3). Disponível em: <http://www.usp. $\mathrm{br} / \mathrm{cpc} / \mathrm{v} 1 /$ imagem/download_arquivo/roteiro3.pdf $>$ Acesso em: 12 abr. 2017.

OBSERVATÓRIO DE MUSEUS E CENTROS CULTURAIS.

Pesquisa perfil-opinião. 2006- 2007: análise descritiva preliminar dos dados agregados dos museus participantes da pesquisa em São Paulo. Rio de Janeiro, 2008.

PUTNAM, R. D. Comunidade e democracia: a experiência da Itália Moderna. Rio de Janeiro: Fundação Getúlio Vargas, 1996.

ROBERTS, L. C. From knowledge to narrative: educators and the changing museum. Washington, London: Smithsonian Institution Press, 1997.

SEIBEL-MACHADO, M. I. O papel do setor educativo nos museus: análise da literatura (1987 a 2006) e a experiência do Museu da Vida. Campinas, 2009. Tese (Doutorado) - Instituto de Geociências, Universidade Estadual de Campinas, 2009.

SOARES, O. GT de Perspectivas Conceituais. In: INSTITUTO BRASILEIRO DE MUSEUS. Documento preliminar da Política Nacional de Educação Museal. Brasília, DF, 2013.

VALENTE, M. E. A. Educação em museu. O público de hoje no museu de ontem. 1995. Dissertação (Mestrado) - Pontifícia Universidade Católica do Rio de Janeiro, Rio de Janeiro, 1995.

Museus de Ciências e Tecnologia no Brasil: uma história da museologia entre as décadas de 1950-1970. 2008. 276 f. Tese (Doutorado) - Instituto de Geociências, Universidade Estadual de Campinas, Campinas, 2008. 


\section{Notas:}

1 Não existem dados de âmbito nacional sobre a frequência a museus no Brasil. Entretanto, dados parciais (OBSERVATORIO DE MUSEUS E CENTROS CULTURAIS, 2008) revelam que apenas 3 a 5\% da população frequenta museus como opção de lazer cultural. 2 As políticas de educação em museus, quando existem, estão relacionadas com a política pedagógica de cada instituição. O termo Policy museum education pode ser encontrado com relativa facilidade na literatura internacional, associado ao planejamento educacional de museus (HOOPER-GREENHILL, 1991; MUSEUMS AND GALLERIES COMMISSION, 2001, entre outros).

3 A ideia de recontextualização pedagógica, cunhada pelo sociólogo da educação Basil Bernstein (1996), busca entender o processo de passagem dos textos pedagógicos de sua esfera inicial de geração - na qual atuam os princípios dominantes da sociedade - para a esfera da transmissão pedagógica.

4 Gestão 2003 - 2006, na presidência de Luís Inácio Lula da Silva. Com a reeleição de Lula em 2007 (a 2010), a equipe técnica do Ministério da Cultura foi reconduzida, o que dá um caráter de média duração para as políticas públicas desenvolvidas na área de museus.

5 Os Grupos de Trabalho foram constituídos a partir dos 9 eixos temáticos do blog: Perspectivas conceituais; Gestão; Profissionais de Educação Museal; Formação, capacitação e qualificação; Redes e parcerias; Estudos e pesquisas; Acessibilidade; Sustentabilidade; e Museus e Comunidade. Como resultado da sistematização das propostas do blog, os Coordenadores resolveram incluir também o GT de Comunicação.

6 Foram realizados encontros nas cidades do Rio de Janeiro (RJ), Juiz de Fora (MG), Manaus (AM), Florianópolis (SC), João Pessoa (PB), Belo Horizonte (MG), Recife (PE), Salvador (BA), Santo Ângelo (RS), Taubaté (SP), Blumenau (SC), Fortaleza (CE), Brasília (DF), São Paulo (SP), Belém (PA) e São Luís (MA).

7 Para que fosse possível discutir as contribuições dos encontros regionais apenas as diretrizes foram condensadas em uma publicação, deixando de fora as estratégias e ações. 